\title{
Aplicação de resíduo alcalino na superfície de Cambissolos
}

\author{
Jackson Adriano Albuquerque ( $\left.{ }^{1 *}\right)$; João Carlos Medeiros ( $\left.{ }^{2}\right)$; André da Costa $\left({ }^{1}\right)$; Maicon Rengel $\left({ }^{3}\right)$ \\ (1) Universidade do Estado de Santa Catarina (UDESC), Centro de Ciências Agroveterinárias, Departamento de Solos e Recursos \\ Naturais, 88520-000 Lages (SC), Brasil. \\ (2) ESALQ/USP, Departamento de Ciência do Solo, Av. Pádua Dias, 11, 13418-970 Piracicaba (SP), Brasil. \\ (3) Cooperativa Regional do Alto Vale do Itajaí, Rio do Sul (SC), Brasil. \\ $\left.{ }^{*}\right)$ Autor correspondente: albuquerque@pq.cnpq.br
}

Recebido: 11/abr./2011; Aceito: 6/jun./2011

\section{Resumo}

A indústria de celulose produz um grande volume de resíduos, e alguns possuem potencial para melhorar a fertilidade dos solos. Entretanto, ainda existe carência de informações sobre a viabilidade de uso e as doses a serem aplicadas ao solo. Os objetivos deste estudo foram avaliar a utilização de um resíduo alcalino (dregs) como corretivo da acidez e quantificar as mudanças nos atributos químicos e físicos em dois Cambissolos, um de textura franco-argilosa e outro de textura francoarenosa. O experimento montado em vasos foi desenvolvido em casa de vegetação, com aplicação superficial de dregs na proporção de 0\%, 12\%, 35\%, 50\% e 100\% da dose equivalente de $\mathrm{CaCO}_{3}$ necessária para elevar o pH até 6,0. A cultura do milho foi cultivada até 40 dias após a germinação para quantificação da matéria seca das raízes e da parte aérea. Em solos não cultivado com milho, amostras foram coletadas para avaliar a estabilidade de agregados, argila dispersa, $\mathrm{pH}$ do solo e teor de cátions trocáveis. A adição superficial de dregs eleva o pH, os teores de $\mathrm{Ca}, \mathrm{K}$ e $\mathrm{Mg}$, e reduz o teor de $\mathrm{Al}$ trocável, principalmente na camada de 0 a $5 \mathrm{~cm}$. No entanto, são observados efeitos prejudicais como o aumento no teor de $\mathrm{Na}$, da relação $\mathrm{Ca} / \mathrm{Mg}$ e da dispersão da argila. As alterações nos atributos químicos do solo favorecem o crescimento das raízes e da parte aérea do milho, até uma dose de dregs equivalente de $40 \%$ a $47 \%$ da necessidade de calcário para elevar o pH em água para 6,0. Doses superiores a essas prejudicam o desenvolvimento das plantas.

Palavras-chave: correção da acidez, dispersão da argila, dregs, Zea Mayz.

\section{Application of alkaline residue on the surface of Cambisols}

\section{Abstract}

The cellulose industry produce a large amount of residues, and some have potential to improve the soil fertility. However, there is still lack of information about the viability of use and the doses to be applied to the soil. The aims of this study were to evaluate the use of an alkaline residue (dregs) as acidity corrective and measure the changes in the chemical and physical attributes of two Cambisols, one clay loam and another sandy loam. The experiment was performed in pots in a greenhouse, with superficial application of dregs in the proportion of $0 \%, 12 \%, 35 \%, 50 \%$ and $100 \%$ of the equivalent rate of $\mathrm{CaCO}_{3}$ required to increase the $\mathrm{pH}$ to 6.0. The maize crop was grown until 40 days after germination to quantify the dry matter of roots and shoots. In soil not cultivated with maize, samples were collected to evaluate the aggregate stability, clay dispersion, $\mathrm{pH}$, and content of exchangeable cations. The addition of surface dregs increases the $\mathrm{pH}, \mathrm{Ca}, \mathrm{K}$ and $\mathrm{Mg}$, and reduces the content of exchangeable Al, mainly in the soil layer of 0 to $5 \mathrm{~cm}$. However, harmful effects are observed, as the increase in the content of $\mathrm{Na}$, the $\mathrm{Ca} / \mathrm{Mg}$ ratio and dispersion of clay. Changes in soil chemical properties favor the growth of roots and shoots of maize until the dose equivalent to the dregs from 40 to $47 \%$ of the need for lime to raise the water pH to 6.0. Above these doses plant development is constrained.

Key words: acidity correction, clay dispersion, dregs, Zea Mayz. 


\section{INTRODUÇÃO}

As indústrias de papel e celulose são responsáveis pela geração de grande quantidade de resíduos sólidos, efluentes hídricos e emissôes gasosas lançados no ambiente (FLORES et al., 1998). Segundo Johnson e Ryder (1988), o volume total de resíduos pode alcançar $200.000 \mathrm{~m}^{3} \mathrm{dia}^{-1} \mathrm{e}$ variar em função do processo de fabricação utilizado.

Dentre os resíduos sólidos, existem o "dregs" e o "grits" com potencial de uso agrícola. Esses resíduos são gerados durante a recuperação dos reagentes químicos utilizados na produção de celulose (SPRINGER, 1993). O dregs é gerado durante o processo de clarificação do licor verde e é constituído basicamente por carbonato de sódio, sulfeto de sódio, carbono não queimado, ferro, sílica, cálcio, alumina, magnésio e sulfetos, com potencial para neutralização da acidez do solo. A análise termogravimétrica confirma a presença de carbonatos (Almeida et al., 2008).

Segundo Pöoykiö et al. (2006) e Albuquerque et al. (2002), o tratamento e a utilização de dregs como corretivo de acidez no solo seriam a melhor alternativa, quando comparados com sua deposição em aterros. No entanto, deve haver a preocupaçáo com relação a este resíduo ter cloro em sua composição e a possibilidade de formar compostos organo-clorados (KoOKana e Rogers, 1995). As reaçôes do resíduo alcalino da indústria de celulose após sua aplicação no solo dependem de sua composiçáo química, o que permite alterar as condiçóes do solo, através da elevação do $\mathrm{pH}$ e adição de macronutrientes e micronutrientes (Correa et al., 2008; ERnANI, 2008). A concentração de micronutrientes catiônicos na solução do solo como $\mathrm{Zn}, \mathrm{Fe}$, $\mathrm{Cu}$ e $\mathrm{Mn}$, e de metais pesados como $\mathrm{Hg}$, $\mathrm{Cd}, \mathrm{Cr}, \mathrm{Pb}$, diminui com a elevação do pH (ERnani, 2008). Além disso, a alta relação $\mathrm{Ca} / \mathrm{Mg}$ deste resíduo pode alterar a disponibilidade de $\mathrm{Mg}$ e K à planta, bem como seu alto teor de $\mathrm{Na}$ dispersar a argila e reduzir a estabilidade de agregados do solo e o grau de floculação (AlbuQuerque et al., 2002), tornando-o menos permeável e mais suscetível ao selamento superficial e à erosão hídrica (Miller e BAHARUddin, 1986; Shainberg e Singer, 1988).

Para identificar as potencialidades e limitaçóes do resíduo alcalino e a forma mais adequada de sua utilização, faz-se necessário estudar seus efeitos sobre o solo. Portanto, objetivou-se com este estudo avaliar o uso de dregs como corretivo da acidez e os efeitos de sua aplicação sobre os atributos químicos e físicos em dois Cambissolos de classes texturais distintas.

\section{MATERIAL E MÉTODOS}

O experimento foi realizado em casa de vegetação, com amostras de dois solos com distinta distribuição granulométrica, um Cambissolo Húmico $(\mathrm{CH})$ de classe textural franco-argilosa e outro Cambissolo Húmico $(\mathrm{CH})$ de classe textural franco-arenosa. $\mathrm{O}$ solo coletado no horizonte $\mathrm{A}$, na camada de 0 a $20 \mathrm{~cm}$, foi homogeneizado e peneirado em malha de $10 \mathrm{~mm}$ antes de ser adicionado em colunas de PVC de $10 \mathrm{~cm}$ de diâmetro e volume de $1.180 \mathrm{~cm}^{3}$, resultando em densidade do solo de $1,05 \mathrm{~g} \mathrm{~cm}^{-3} \mathrm{e} 1,26 \mathrm{~g} \mathrm{~cm}^{-3}$ respectivamente para o Cambissolo de textura franco-argilosa e o de textura franco-arenosa. Na tabela 1 estão relacionados os dados das análises básicas dos dois solos.

Em cada solo foi testado o efeito de cinco doses de resíduo alcalino em três camadas de solo sobrepostas na mesma coluna, sendo o delineamento inteiramente casualizado, com seis unidades experimentais por tratamento. Três repetiçóes foram utilizadas para avaliar os atributos químicos e físicos do solo e três para avaliar o desenvolvimento de plantas de milho.

$\mathrm{Na}$ superfície do solo foram aplicadas doses de resíduo alcalino que corresponderam a $0 \%, 12 \%, 35 \%, 50 \%$ e $100 \%$ da necessidade de $\mathrm{CaCO}_{3}$ a ser incorporado ao solo, para elevar o pH a 6,0 na camada de $0-20 \mathrm{~cm}$, segundo a Comissão de Química e Fertilidade do Solo - RS/SC (2004). As doses de 100\% corresponderam à necessidade de $21.000 \mathrm{~kg} \mathrm{ha}^{-1} \mathrm{de} \mathrm{CaCO}_{3}$ para o Cambissolo Húmico franco-argiloso e de $9.900 \mathrm{~kg} \mathrm{ha}^{-1}$ de $\mathrm{CaCO}_{3}$ para o Cambissolo Húmico franco-arenoso.

A concentração de elementos químicos do resíduo (Tabela 2) foi determinada por AlmeidA et al. (2008). O valor de neutralizaçáo do dregs utilizado é de $80 \%$ e o pH de 10,7 (Almeida et al., 2008) determinados segundo Tedesco et al. (I995). Para cada coluna, a quantidade de dregs adicionada, para a dose correspondente a $100 \%$, foi de 16,5 g para o $\mathrm{CH}$ franco-argiloso e 7,7 g para o $\mathrm{CH}$ franco-arenoso. Por conseguinte, as doses de resíduo aplicadas para o Cambissolo Húmico franco-argiloso foram de 0, 3.360 (12\%), 9.800 (25\%), $14.000(50 \%)$ e $28.000 \mathrm{~kg} \mathrm{ha}^{-1}(100 \%)$ e para o Cambissolo Húmico franco-arenoso foram de 0, 1.572 (12\%), 4.585 (25\%), 6.550 (50\%) e $13.100 \mathrm{~kg} \mathrm{ha}^{-1}(100 \%)$.

A umidade do solo foi mantida próximo da capacidade de campo (GARDNER, 1986), a qual foi determinada previamente através da saturação de colunas de solo, seguido da drenagem por dois dias e determinação da

Tabela 1. Atributos químicos e físicos do Cambissolo Húmico de textura franco-argilosa e do Cambissolo Húmico de textura francoarenosa, coletados na camada de 0 a $20 \mathrm{~cm}$ do horizonte A

\begin{tabular}{|c|c|c|c|c|c|c|c|c|c|c|}
\hline Solo & $\mathrm{pH}_{\mathrm{H} 2 \mathrm{O}}$ & $\mathrm{Ca}$ & Mg & K & $\mathrm{Na}$ & Al & CTC $_{\text {efet }}$ & Areia & Silte & Argila \\
\hline & & \multicolumn{6}{|c|}{$\left(\mathrm{cmol}_{\mathrm{c}} \mathrm{kg}^{-1}\right)$} & \multicolumn{3}{|c|}{$\left(\mathrm{g} \mathrm{kg}^{-1}\right)$} \\
\hline $\begin{array}{l}\text { Cambissolo Húmico } \\
\text { Franco-argiloso }\end{array}$ & 4,1 & 0,5 & 0,10 & 0,13 & 0,01 & 6,8 & 7,5 & 343 & 325 & 332 \\
\hline $\begin{array}{l}\text { Cambissolo Húmico } \\
\text { Franco-arenoso }\end{array}$ & 4,5 & 0,3 & 0,12 & 0,13 & 0,02 & 2,2 & 2,8 & 744 & 120 & 136 \\
\hline
\end{tabular}


Tabela 2. Concentração dos elementos químicos presentes no dregs. Média de cinco repetições

\begin{tabular}{lc|} 
Elemento & $\begin{array}{c}\text { Concentração } \\
\left(\mathrm{g} \mathrm{kg}^{-1}\right)\end{array}$ \\
\hline $\mathrm{Ca}$ & 354 \\
$\mathrm{Mg}$ & 9,2 \\
$\mathrm{Na}$ & 10,2 \\
$\mathrm{~K}$ & 1,2 \\
$\mathrm{Fe}$ & 3,0 \\
$\mathrm{Mn}$ & 4,8 \\
\hline $\mathrm{Zn}$ & $\left(\mathrm{mg} \mathrm{kg}^{-1}\right)$ \\
$\mathrm{Cu}$ & 235 \\
$\mathrm{~Pb}$ & 54 \\
$\mathrm{Cd}$ & 63 \\
\hline
\end{tabular}

Fonte: Almeida et al. (2008).

umidade gravimétrica. Devido à elevada demanda por água no interior da casa de vegetaçâo era necessário monitorar a umidade diariamente. As amostras com e sem cultivo de milho foram irrigadas no período de 40 dias.

Nas colunas cultivadas foram semeadas três sementes do milho Cargill 901, híbrido simples de ciclo superprecoce. Transcorridos 40 dias após a semeadura, a parte aérea e as raízes foram coletadas separadamente para determinar a massa seca $\left(65^{\circ} \mathrm{C}\right.$ até massa constante).

Nas colunas não cultivadas com milho foram determinados os atributos químicos e físicos nas camadas de 0-5, 5-10 e 10-15 cm. Os elementos $\mathrm{Na}$ e $\mathrm{K}$ foram extraídos com acetato de amônio e quantificados por fotometria de chama; $\mathrm{Ca}$ e $\mathrm{Mg}$ foram extraídos com cloreto de potássio e quantificados por espectrofotometria de absorção atômica; o Al trocável foi extraído com cloreto de potássio e quantificado por titulometria de neutralização com $\mathrm{NaOH}$; soma de bases (SB), saturação por $\mathrm{Al}(\mathrm{m})$ e $\mathrm{CTC}_{\text {efet }}$ foram calculados conforme Embrapa (1997); o $\mathrm{pH}$ em água foi determinado na relação solo:solução 1:1 com leituras em potenciômetro (Tedesco et al., 1995).

A estabilidade de agregados foi determinada pelo método de Kemper e Rosenou (1986), com agregados com tamanho inicial entre um e dois milímetros, e o resultado expresso pelo índice estabilidade de agregados, sendo a faixa de variação do índice é de zero (menor estabilidade) a um (maior estabilidade). Foi medido o teor de argila total dispersa em $\mathrm{NaOH} 1 \mathrm{~N}$ (AT), e o teor de argila dispersa em água $(\mathrm{AD})$ através do método do densímetro (GeE e BAUDER, 1986) e calculado o grau de floculação $(\mathrm{GF})$, conforme a equação: $\mathrm{GF}=(\mathrm{AT}-\mathrm{AD}) / \mathrm{AT}$.

A análise estatística foi realizada para cada solo, através da análise de variância (teste $F$ ) para os atributos de solo e de planta, delineamento inteiramente casualizado com três repetiçóes. Para os atributos de solo, a análise foi realizada individualmente em cada uma das três camadas avaliadas. Para os atributos de solo e de planta foram ajustadas equaçóes de regressão com o fator quantitativo (doses de dregs), obtendo-se equaçóes lineares ou polinomiais de segunda ordem, conforme o grau de significância obtido $(\mathrm{p}<0,05)$. A relação entre os atributos foi avaliada através do teste de correlação de Pearson. Todas as análises foram realizadas através do "sistema de análises estatísticas" (SAS, 2002).

\section{RESULTADOS E DISCUSSÃO}

Houve efeito de doses sobre os atributos nos dois solos (Tabela 3). O teor de sódio $(\mathrm{Na})$ trocável aumentou de forma quadrática na camada superficial e linear nas demais camadas do $\mathrm{CH}$ franco-arenoso, e linear nas três camadas do $\mathrm{CH}$ franco-argiloso (Figura 1a,b), concordando com os resultados observados no campo por MedeIros et al. (2009) em um Cambissolo Húmico alumínico franco-argiloso. A elevação dos teores de $\mathrm{Na}$ nas três camadas avaliadas é atribuída à sua alta mobilidade no solo. Na camada superficial, os teores de $\mathrm{Na}$ aumentaram de $0,01 \mathrm{cmol}_{\mathrm{c}} \mathrm{kg}^{-1}$ na testemunha para $1,2 \mathrm{cmol}_{\mathrm{c}} \mathrm{kg}^{-1}$ na maior dose aplicada para o $\mathrm{CH}$ franco-argiloso, enquanto no $\mathrm{CH}$ franco-arenoso, o aumento foi de 0,02 para $0,8 \mathrm{cmol}_{\mathrm{c}} \mathrm{kg}^{-1}$. O aumento no teor de $\mathrm{Na}$, nas camadas de 5 a 10 e 10 a $15 \mathrm{~cm}$, foi menor comparado ao da primeira camada e com menor intensidade no CH franco-arenoso. Albuquerque et al. (2002) também constataram maiores teores de $\mathrm{Na}$ na camada de 0 a $5 \mathrm{~cm}$ com a dose de dregs correspondente a $50 \%$ de $\mathrm{CaCO}_{3}$ em um Latossolo e um Cambissolo em colunas, com menores aumentos na camada de 5 e $10 \mathrm{~cm}$.

A causa deste aumento é atribuída aos teores elevados desse elemento na composição do resíduo, cuja concentração era de $10,2 \mathrm{~g} \mathrm{~kg}^{-1}$ de $\mathrm{Na}$ (Tabela 2). Com este teor, na maior dose de dregs foi adicionado $285 \mathrm{~kg} \mathrm{ha}^{-1} \mathrm{de} \mathrm{Na}$ no $\mathrm{CH}$ franco-argiloso e $133 \mathrm{~kg} \mathrm{ha}^{-1} \mathrm{de} \mathrm{Na}$ no $\mathrm{CH}$ franco-arenoso.

Com a adição de dregs, o teor de potássio trocável do solo $(\mathrm{K})$ aumentou linearmente com as doses no $\mathrm{CH}$ franco-argiloso na camada de 0 a $5 \mathrm{~cm}$ e de forma quadrática no $\mathrm{CH}$ franco-arenoso nas camadas de 0 a 5 e 5 a $10 \mathrm{~cm}$ (Tabelas 3 e 4), mantendo-se constante nas demais camadas. O acréscimo nos teores de potássio do solo deve-se ao potássio proveniente do resíduo alcalino, cuja concentração é de $1,2 \mathrm{~g} \mathrm{~kg}^{-1}$. Em termos de interpretaçáo dos teores de $\mathrm{K}$ do solo, segundo a CQFS-RS/SC (2004), considerando ambos os solos com $\mathrm{CTC}_{\text {efet }}$ entre 5 e $15 \mathrm{cmol} \mathrm{dm}_{\mathrm{c}} \mathrm{dm}^{-3}$, o teor de K na camada de 0 a $5 \mathrm{~cm}$ aumentou de "médio" na testemunha para "muito alto" na maior dose de dregs. Através das equaçôes ajustadas para predizer os teores de $\mathrm{K}$ do solo, observa-se que, para a elevação dos teores de $\mathrm{K}$ para o nível de suficiência $\left(60 \mathrm{mg} \mathrm{dm}^{-3}\right)$, na camada de 0 a $5 \mathrm{~cm}$, seria necessário a aplicação superficial de 1,9 ou $0,5 \mathrm{Mg} \mathrm{ha}^{-1}$ de dregs, respectivamente, no $\mathrm{CH}$ franco-argiloso ou $\mathrm{CH}$ franco-arenoso. Para a elevação dos teores de K para o nível "alto" (120 $\left.\mathrm{mg} \mathrm{dm}^{-3}\right)$ na camada de 0 a $5 \mathrm{~cm}$, deve-se adicionar as doses de 23,4 e 9,3 $\mathrm{Mg} \mathrm{ha}^{-1}$ de dregs, respectivamente no $\mathrm{CH}$ franco-argiloso ou $\mathrm{CH}$ franco-arenoso. $\mathrm{Na}$ camada 
Tabela 3. Atributos físicos e químicos do Cambissolo Húmico de textura franco-argiloso e do Cambissolo Húmico de textura francoarenosa, após incubação do solo com resíduo alcalino da indústria de papel e celulose, Lages

\begin{tabular}{|c|c|c|c|c|c|c|c|c|c|}
\hline Dose & Camada & $\mathbf{K}^{(1)}$ & $\mathrm{Ca}$ & Mg & SB & CTC $_{\text {efet }}$ & Al & $\mathrm{pH}_{\mathrm{H} 2 \mathrm{O}}$ & IEA \\
\hline$\%$ SMP (2) & $(\mathrm{cm})$ & & & & & & & & . \\
\hline \multicolumn{10}{|c|}{ Cambissolo Húmico franco-argiloso } \\
\hline \multirow{3}{*}{0} & 0 a 5 & 0,14 & 0,7 & 0,1 & 0,9 & 7,5 & 6,6 & 4,2 & 0,95 \\
\hline & 5 a 10 & 0,13 & 0,4 & 0,1 & 0,6 & 7,2 & 6,7 & 4,1 & 0,97 \\
\hline & 10 a 15 & 0,12 & 0,4 & 0,1 & 0,6 & 7,7 & 7,0 & 4,1 & 0,93 \\
\hline \multirow{3}{*}{12} & 0 a 5 & 0,17 & 2,0 & 0,2 & 2,6 & 6,5 & 3,9 & 4,9 & 0,94 \\
\hline & 5 a 10 & 0,11 & 0,5 & 0,1 & 0,7 & 8,2 & 7,5 & 4,4 & 0,94 \\
\hline & 10 a 15 & 0,11 & 0,4 & 0,1 & 0,6 & 7,3 & 6,7 & 4,2 & 0,96 \\
\hline \multirow{3}{*}{35} & 0 a 5 & 0,20 & 4,6 & 0,4 & 5,6 & 6,9 & 0,9 & 5,5 & 0,93 \\
\hline & 5 a 10 & 0,10 & 0,5 & 0,1 & 0,7 & 7,1 & 6,4 & 4,5 & 0,90 \\
\hline & 10 a 15 & 0,09 & 0,4 & 0,1 & 0,6 & 7,2 & 6,5 & 4,4 & 0,94 \\
\hline \multirow{3}{*}{50} & 0 a 5 & 0,27 & 6,2 & 0,4 & 7,6 & 7,7 & 0,1 & 5,9 & 0,90 \\
\hline & 5 a 10 & 0,12 & 0,6 & 0,1 & 1,0 & 7,4 & 6,3 & 4,6 & 0,90 \\
\hline & 10 a 15 & 0,11 & 0,5 & 0,1 & 0,7 & 6,9 & 6,2 & 4,5 & 0,93 \\
\hline \multirow{3}{*}{100} & 0 a 5 & 0,34 & 8,5 & 0,4 & 10,4 & 10,4 & 0,0 & 6,7 & 0,93 \\
\hline & 5 a 10 & 0,13 & 0,6 & 0,1 & 1,1 & 6,8 & 5,7 & 4,7 & 0,96 \\
\hline & 10 a 15 & 0,12 & 0,5 & 0,1 & 1,0 & 7,6 & 6,7 & 4,5 & 0,88 \\
\hline \multicolumn{10}{|c|}{ Tipo de regressão ajustada (3) } \\
\hline & 0 a 5 & $L^{* *(4)}$ & $Q^{* *}$ & $Q^{* *}$ & $\mathrm{Q}^{* *}$ & $Q^{* *}$ & $Q^{* *}$ & $\mathrm{Q}^{* *}$ & $Q^{* *}$ \\
\hline & 5 a 10 & ns & $L^{* *}$ & ns & $L^{* *}$ & ns & $L^{* *}$ & $\mathrm{Q}^{* *}$ & $L^{* *}$ \\
\hline & 10 a 15 & ns & $L^{* *}$ & ns & $L^{* *}$ & $Q^{* *}$ & $Q^{* *}$ & $Q^{* *}$ & $L^{* *}$ \\
\hline \multicolumn{10}{|c|}{ Cambissolo Húmico franco-arenoso } \\
\hline \multirow{3}{*}{0} & 0 a 5 & 0,14 & 0,5 & 0,2 & 0,8 & 2,6 & 1,9 & 4,7 & 0,93 \\
\hline & 5 a 10 & 0,13 & 0,3 & 0,1 & 0,6 & 2,9 & 2,3 & 4,5 & 0,91 \\
\hline & 10 a 15 & 0,13 & 0,3 & 0,1 & 0,5 & 2,8 & 2,3 & 4,4 & 0,92 \\
\hline \multirow{3}{*}{12} & 0 a 5 & 0,17 & 1,5 & 0,2 & 2 & 2,9 & 0,9 & 5,4 & 0,92 \\
\hline & 5 a 10 & 0,13 & 0,3 & 0,1 & 0,6 & 2,9 & 2,3 & 4,8 & 0,92 \\
\hline & 10 a 15 & 0,13 & 0,3 & 0,1 & 0,6 & 3,0 & 2,5 & 4,6 & 0,91 \\
\hline \multirow{3}{*}{35} & 0 a 5 & 0,19 & 2,2 & 0,3 & 2,8 & 2,8 & 0 & 6,0 & 0,88 \\
\hline & 5 a 10 & 0,13 & 0,4 & 0,1 & 0,6 & 2,7 & 2,1 & 4,9 & 0,94 \\
\hline & 10 a 15 & 0,14 & 0,3 & 0,1 & 0,6 & 2,9 & 2,3 & 4,7 & 0,93 \\
\hline \multirow{3}{*}{50} & 0 a 5 & 0,23 & 2,6 & 0,3 & 3,4 & 3,4 & 0 & 6,1 & 0,82 \\
\hline & 5 a 10 & 0,13 & 0,4 & 0,1 & 0,7 & 2,8 & 2,2 & 4,9 & 0,77 \\
\hline & 10 a 15 & 0,13 & 0,3 & 0,1 & 0,6 & 2,9 & 2,3 & 4,8 & 0,93 \\
\hline \multirow{3}{*}{100} & 0 a 5 & 0,40 & 4,1 & 0,4 & 5,7 & 5,7 & 0 & 7,5 & 0,90 \\
\hline & 5 a 10 & 0,15 & 0,5 & 0,1 & 0,9 & 2,2 & 1,3 & 5,0 & 0,89 \\
\hline & 10 a 15 & 0,14 & 0,4 & 0,1 & 0,7 & 2,8 & 2,1 & 4,7 & 0,93 \\
\hline \multicolumn{10}{|c|}{ Tipo de regressão ajustada (3) } \\
\hline & 0 a 5 & $Q^{* *(4)}$ & $L^{* *}$ & $L^{* *}$ & $\mathrm{~L}^{* *}$ & $Q^{* *}$ & $\mathrm{Q}^{* *}$ & $L^{* *}$ & $Q^{* *}$ \\
\hline & 5 a 10 & $\mathrm{Q}^{* *}$ & $L^{* *}$ & ns & $\mathrm{Q}^{* *}$ & $L^{* *}$ & $L^{* *}$ & $\mathrm{Q}^{* *}$ & $Q^{* *}$ \\
\hline & 10 a 15 & ns & $L^{* *}$ & $\mathrm{Q}^{* *}$ & $\mathrm{~L}^{* *}$ & ns & $\mathrm{L}^{* *}$ & $\mathrm{Q}^{* *}$ & $L^{* *}$ \\
\hline
\end{tabular}

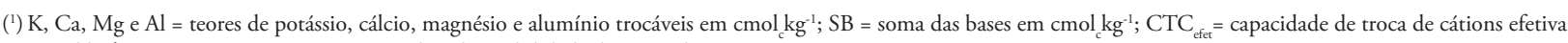
em $\mathrm{cmol} \mathrm{kg}{ }^{-1} ; \mathrm{pH}_{\mathrm{H} 20}=\mathrm{pH}$ em água; IEA = índice de estabilidade de agregados.

${ }^{(2)}$ Dose $=\%$ da dose de dregs correspondente a necessidade de calcário para elevar o $\mathrm{pH}_{\mathrm{H} 2 \mathrm{O}}$ para 6,0 na camada de $0-20 \mathrm{~cm}, 100 \%=28.000 \mathrm{~kg}$ ha ${ }^{-1}$ de dregs no $\mathrm{CH}$ francoargiloso e $13.100 \mathrm{~kg} \mathrm{ha}^{-1}$ no $\mathrm{CH}$ franco-arenoso.

$\left({ }^{3}\right) \mathrm{L}=$ ajuste de regressão linear ou $\mathrm{Q}=$ ajuste de regressão quadrática.

${ }^{(4)}$ ns $=$ nấo significativo $(\mathrm{p}>0,05) ;^{*}=$ significativo $(0,01<\mathrm{p}<0,05) \mathrm{e}^{* *}=$ significativo $(\mathrm{p}<0,01)$ pelo teste $\mathrm{F}$. 
(a)

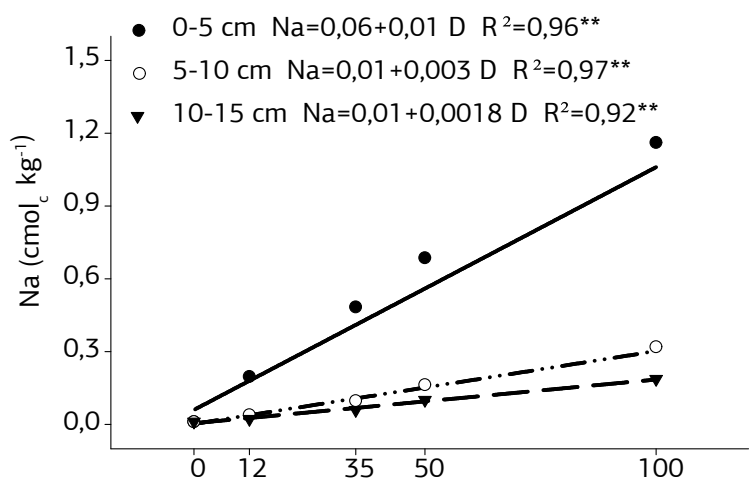

(c)

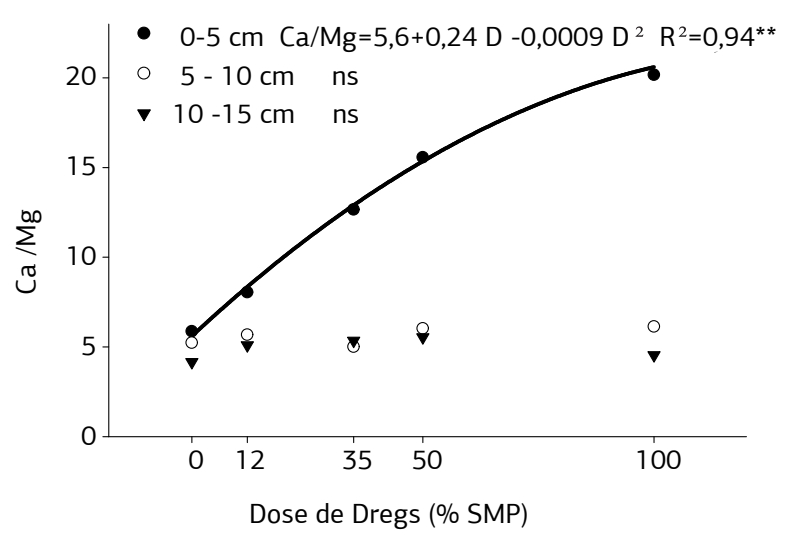

(b)

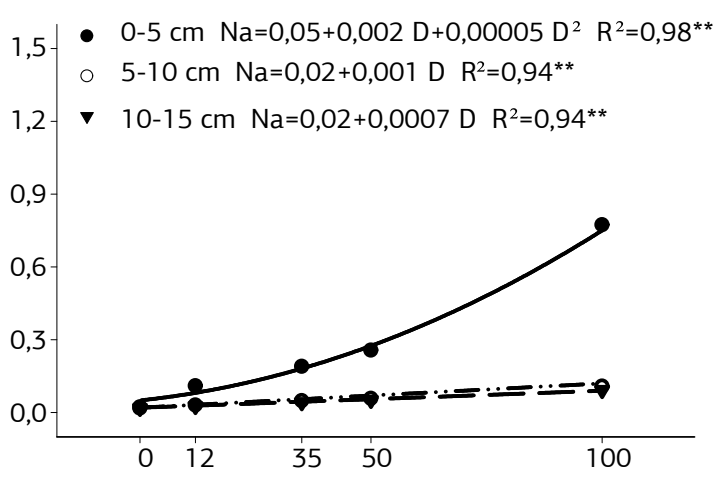

(d)

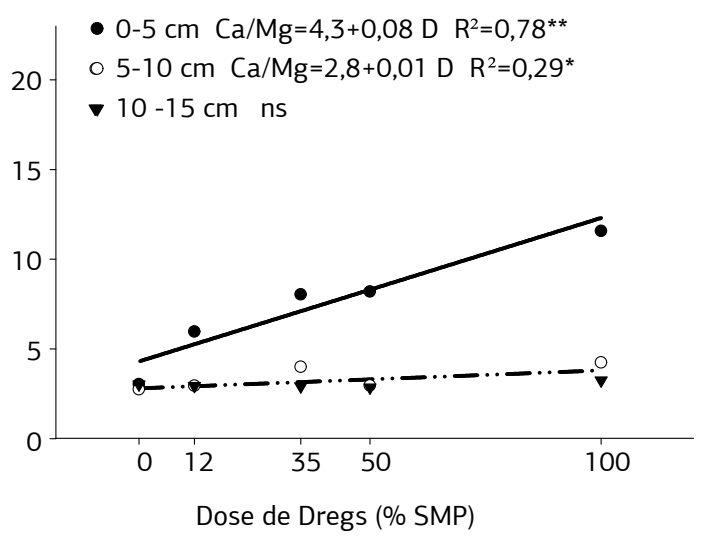

Figura 1. Teor de sódio $(\mathrm{Na})$ e relação cálcio/magnésio $(\mathrm{Ca} / \mathrm{Mg})$, do Cambissolo Húmico de textura franco-argilosa (a, c) e do Cambissolo Húmico de textura franco-arenosa (b, d), após incubação do solo com resíduo alcalino da indústria de papel e celulose, Lages (SC). D = $\%$ da dose de dregs correspondente a necessidade de calcário para elevar o $\mathrm{pH}_{\mathrm{H} 2 \mathrm{O}}$ para 6,0 na camada de $0-20 \mathrm{~cm}, 100 \%=28.000 \mathrm{~kg} \mathrm{ha}{ }^{-1}$ de dregs no $\mathrm{CH}$ franco-argiloso e $13.100 \mathrm{~kg} \mathrm{ha}^{-1}$ no $\mathrm{CH}$ franco-arenoso. ns = náo significativo; ${ }^{*}=$ significativo $(0,01<\mathrm{p}<0,05) ;{ }^{* *}=$ significativo $(\mathrm{p}<0,01)$. Cada ponto representa a média de três repetiçôes.

de 5 a $10 \mathrm{~cm}$ do $\mathrm{CH}$ franco-argiloso, a adição de $13 \mathrm{Mg} \mathrm{ha}^{-1}$ de dregs aumentou o teor de $\mathrm{K} \mathrm{em}$ apenas $4,0 \mathrm{mg} \mathrm{dm}^{-3}$.

No trabalho de Albuquerque et al. (2002) com aplicação de dregs na superfície de colunas com dois solos, um Latossolo Bruno distrófico e um Cambissolo Húmico alumínico, também houve aumento do teor de $\mathrm{K}$, na camada de 0 a $5 \mathrm{~cm}$, após dois meses da aplicação.

O teor de cálcio trocável $(\mathrm{Ca})$ no $\mathrm{CH}$ franco-argiloso aumentou de forma quadrática na primeira camada e de forma linear nas demais camadas, e no $\mathrm{CH}$ franco-arenoso aumentou de forma linear em todas as camadas (Tabelas 3 e 4). Esse aumento deve-se à grande quantidade de $\mathrm{Ca}$ adicionada com aplicação superficial de dregs, cuja concentração era de $354 \mathrm{~g} \mathrm{~kg}^{-1}$, aplicando-se na maior dose, $9.912 \mathrm{~kg} \mathrm{ha}^{-1}$ no $\mathrm{CH}$ franco-argiloso e $4.637 \mathrm{~kg} \mathrm{ha}^{-1}$ no $\mathrm{CH}$ franco-arenoso.

Os maiores teores de Ca do solo foram nas doses máximas para ambos os solos nas três camadas avaliadas. Entretanto, houve reduçáo da amplitude entre a testemunha e a maior dose de dregs com o aumento da profundidade, indicando uma baixa mobilidade deste cátion no perfil do solo. Em relaçáo à testemunha, o aumento do teor de Ca trocável foi maior na camada superficial do $\mathrm{CH}$ franco-argiloso $(1.114 \%)$ do que do $\mathrm{CH}$ franco-arenoso (720\%), devido à maior dose aplicada e o menor teor de Ca na testemunha do $\mathrm{CH}$ franco-argiloso. No entanto, o aumento do teor de $\mathrm{Ca}$ nas camadas subsuperficiais foi menor no $\mathrm{CH}$ francoargiloso, indicando uma menor mobilidade do Ca no perfil devido à maior capacidade de retenção de cátions (CTC).

Com base nas equaçóes ajustadas para a camada superficial $(0$ a $5 \mathrm{~cm})$, a adição de uma dose de dregs de $8.000 \mathrm{~kg} \mathrm{ha}^{-1}$ no $\mathrm{CH}$ franco-argiloso seria suficiente para elevar o teor de Ca do solo para a faixa de interpretação "alto", segundo a CQFS-RS/SC (2004); no $\mathrm{CH}$ franco-arenoso seria necessário uma dose de dregs de $12.200 \mathrm{~kg} \mathrm{ha}^{-1}$. Para as camadas de 0 a 5 e 5 a $10 \mathrm{~cm}$, o nível de Ca ficou nas faixas de interpretação "muito baixo" e "baixo", desde a testemunha até a maior dose aplicada.

A adição de dregs aumentou linearmente os teores de magnésio trocável $(\mathrm{Mg})$ na camada superficial do $\mathrm{CH}$ franco-arenoso, e de forma quadrática na camada de 10 a $15 \mathrm{~cm}$ desse solo e na camada de 0 a $5 \mathrm{~cm}$ do $\mathrm{CH}$ franco-argiloso (Tabela 4). Os teores aumentaram de 0,1 a $0,4 \mathrm{cmol}_{\mathrm{c}} \mathrm{kg}^{-1}$, 
no $\mathrm{CH}$ franco-argiloso, e de 0,2 a $0,4 \mathrm{cmol}_{\mathrm{c}} \mathrm{kg}^{-1}$, no $\mathrm{CH}$ franco-arenoso, da menor para a maior dose aplicada respectivamente (Tabela 3). No CH franco-argiloso a quantidade de $\mathrm{Mg}$ adicionada na maior dose $\left(28.000 \mathrm{~kg} \mathrm{ha}^{-1}\right)$ foi de $258 \mathrm{~kg} \mathrm{ha}^{-1}$, e no $\mathrm{CH}$ franco-arenoso na maior dose $\left(13.100 \mathrm{~kg} \mathrm{ha}^{-1}\right)$ foi de $121 \mathrm{~kg} \mathrm{ha}^{-1}$. Consequentemente, a aplicação superficial de dregs foi ineficiente para a correção da deficiência de $\mathrm{Mg}$ nos solos estudados, pois, os teores permaneceram na faixa de interpretação "baixo" (CQFS-RS/SC, 2004), em todas as camadas e doses avaliadas, mesmo após a aplicação de doses altas do resíduo.

Medeiros et al. (2009) constataram aumento linear dos teores de $\mathrm{Ca}$ e $\mathrm{Mg}$ até $15 \mathrm{~cm}$ de profundidade com o aumento das doses de dregs aplicadas em superfície em um Cambissolo Húmico. Já em trabalho em ambiente controlado, Albuquerque et al. (2002) tiveram aumento desses cátions até $5 \mathrm{~cm}$, provavelmente devido à ausência de precipitaçáo pluvial com quantidades variadas ao longo do ano.

A relaçáo $\mathrm{Ca} / \mathrm{Mg}$ aumentou na camada de 0 a $5 \mathrm{~cm}$ (Figura 1c,d), de 6 na testemunha para 20 na maior dose no $\mathrm{CH}$ franco-argiloso e de 3 para 12 no $\mathrm{CH}$ franco-arenoso. $\mathrm{Na}$ camada de 5 a $10 \mathrm{~cm}$, somente no $\mathrm{CH}$ francoarenoso foi observado aumento da relação $\mathrm{Ca} / \mathrm{Mg}$ de 2,7 na testemunha para 4,0 na maior dose de dregs. O aumento ocorre pela maior concentração de $\mathrm{Ca}$ em detrimento do $\mathrm{Mg}$ na composiçáo química do dregs, o qual possui uma relaçáo $\mathrm{Ca} / \mathrm{Mg}$ de 38 (Tabela 2).
Segundo a CQFS RS-SC (2004), a maior parte das culturas não é afetada por relações $\mathrm{Ca} / \mathrm{Mg}$ variando de 0,5 até mais de 10, desde que nenhum dos dois nutrientes esteja em deficiência no solo. Teores de $\mathrm{Ca}$ e $\mathrm{Mg}$ inferiores a, respectivamente, 2,0 e $0,5 \mathrm{cmol}_{\mathrm{c}} \mathrm{kg}^{-1}$, são considerados deficientes.

$\mathrm{A}$ adição de dregs elevou linearmente o $\mathrm{pH}$ em água $\left(\mathrm{pH}_{\text {agua }}\right)$ na camada 0 a $5 \mathrm{~cm}$ do $\mathrm{CH}$ franco-arenoso e de forma quadrática nas camadas de 5 a 10 e 10 a $15 \mathrm{~cm}$ deste solo e nas três camadas do $\mathrm{CH}$ franco-argiloso (Figura 2a,b). Na primeira camada do $\mathrm{CH}$ franco-argiloso o $\mathrm{pH}$ aumentou de 4,2 para 6,7 na maior dose de dregs, enquanto no $\mathrm{CH}$ franco-arenoso, aumentou de 4,7 para 7,5 (Tabela 3). Para elevar o $\mathrm{pH}$ em $\mathrm{H}_{2} \mathrm{O}$ do solo para 6,0, com base nas equaçóes obtidas para a camada de 0 a $5 \mathrm{~cm}$, seriam necessários $5,5 \mathrm{Mg} \mathrm{ha}^{-1}$ de dregs para o $\mathrm{CH}$ francoarenoso e $17 \mathrm{Mg} \mathrm{ha}^{-1}$ para o $\mathrm{CH}$ franco-argiloso. Essas doses equivalem a $42 \%$ e $61 \%$ das doses máximas aplicadas de dregs no $\mathrm{CH}$ franco-arenoso e do $\mathrm{CH}$ franco-argiloso respectivamente. Entretanto, nas camadas de 5 a $10 \mathrm{~cm}$ e $10 \mathrm{a} 15 \mathrm{~cm}$, em nenhuma das doses aplicadas houve elevação do $\mathrm{pH}$ em $\mathrm{H}_{2} \mathrm{O}$ para valores iguais ou superiores a 5,5 e o maior $\mathrm{pH}$ ficou próximo de cinco. Portanto, quando for necessário corrigir a acidez do solo em camadas mais profundas, deve-se fazer a incorporaçáo do corretivo, principalmente em solos com elevado poder tampão.

Medeiros et al. (2009), três meses após a aplicação de uma dose de dregs correspondente a $25 \% \mathrm{CaCO}_{3}$,

Tabela 4. Equações de regressão dos atributos químicos do Cambissolo Húmico de textura franco-argilosa e do Cambissolo Húmico de textura franco-arenosa, após incubaçáo do solo com resíduo alcalino da indústria de papel e celulose, Lages (SC)

\begin{tabular}{|c|c|c|c|}
\hline Atributo & Camada (cm) & Cambissolo Húmico franco-argiloso & Cambissolo Húmico franco-arenoso \\
\hline \multirow{3}{*}{$\mathrm{K}^{(1)}$} & 0 a 5 & $\mathrm{~K}=0,14+0,002 \mathrm{D}^{(2)} \mathrm{R}^{2}=0,89^{* *(3)}$ & $K=0,15+0,0008 D+0,00002 D^{2} \quad R^{2}=0,99 * *$ \\
\hline & 5 a 10 & ns & $K=0,13-0,0004 D+0,000005 D^{2} \quad R^{2}=0,63^{* *}$ \\
\hline & 10 a 15 & ns & ns \\
\hline \multirow{3}{*}{$\mathrm{Ca}$} & 0 a 5 & $\mathrm{Ca}=0,5+0,14 \mathrm{D}-0,0006 \mathrm{D}^{2} \mathrm{R}^{2}=0,92^{* *}$ & $\mathrm{Ca}=0,8+0,03 \mathrm{D} \mathrm{R}^{2}=0,95^{* *}$ \\
\hline & 5 a 10 & $\mathrm{Ca}=0,4+0,002 \mathrm{D} \mathrm{R}^{2}=0,42^{* *}$ & $\mathrm{Ca}=0,3+0,002 \mathrm{D} \mathrm{R}^{2}=0,75^{* *}$ \\
\hline & 10 a 15 & $\mathrm{Ca}=0,4+0,001 \mathrm{D} \mathrm{R}^{2}=0,63^{* *}$ & $\mathrm{Ca}=0,3+0,0008 \mathrm{D} \mathrm{R}^{2}=0,41^{*}$ \\
\hline \multirow{3}{*}{$\mathrm{Mg}$} & 0 a 5 & $M g=0,1+0,008 D-0,00005 D^{2} R^{2}=0,88^{* *}$ & $\mathrm{Mg}=0,2+0,002 \mathrm{D} \quad \mathrm{R}^{2}=0,55^{* *}$ \\
\hline & 5 a 10 & ns & ns \\
\hline & 10 a 15 & ns & $M g=0,2+0,001 D-0,000005 D^{2} R^{2}=0,51$ * \\
\hline \multirow{3}{*}{ SB } & 0 a 5 & $S B=0,8+0,17 D-0,0007 D^{2} R^{2}=0,94^{* *}$ & $\mathrm{SB}=1,1+0,05 \mathrm{D} \quad \mathrm{R}^{2}=0,96^{* *}$ \\
\hline & 5 a 10 & $S B=0,6+0,01 \quad D \quad R^{2}=0,75^{* *}$ & $S B=0,6+0,001 D+0,000025 D^{2} R^{2}=0,91^{* *}$ \\
\hline & 10 a 15 & $\mathrm{SB}=0,6+0,004 \mathrm{DR}^{2}=0,73^{* *}$ & $\mathrm{SB}=0,5+0,002 \mathrm{D} \quad \mathrm{R}^{2}=0,61^{* *}$ \\
\hline \multirow{3}{*}{$\mathrm{CTC}_{\text {efet }}$} & 0 a 5 & $C T C_{\text {efet }}=7,2-0,03 D+0,0007 D^{2} R^{2}=0,67^{* *}$ & $\mathrm{CTC}_{\text {efet }}=2,7-0,004 \mathrm{D}+0,0003 \mathrm{D}^{2} \mathrm{R}^{2}=0,95^{* *}$ \\
\hline & 5 a 10 & ns & $\mathrm{CTC}_{\text {efet }}=2,9-0,01 \mathrm{D} \quad \mathrm{R}^{2}=0,45^{* *}$ \\
\hline & 10 a 15 & $C T C_{\text {efet }}=7,6-0,025 D+0,00025 D^{2} R^{2}=0,67^{* *}$ & ns \\
\hline \multirow{3}{*}{ Al } & 0 a 5 & $\mathrm{Al}=6,4-0,2 \mathrm{D}+0,0014 \mathrm{D}^{2} \quad \mathrm{R}^{2}=0,96^{* *}$ & $A l=1,7-0,06 D+0,0004 D^{2} \quad R^{2}=0,95^{* *}$ \\
\hline & 5 a 10 & $A l=7,0-0,01 \quad D \quad R^{2}=0,40^{*}$ & $\mathrm{Al}=2,4-0,01 \mathrm{D} \quad \mathrm{R}^{2}=0,64^{* *}$ \\
\hline & 10 a 15 & $A l=7,0-0,026 D+0,0002 D^{2} \quad R^{2}=0,71^{* *}$ & $\mathrm{Al}=2,4-0,003 \mathrm{D} \quad \mathrm{R}^{2}=0,58^{* *}$ \\
\hline \multirow{3}{*}{ IEA } & 0 a 5 & ns & $\mathrm{IEA}=0,94-0,0036 \mathrm{D}+0,00003 \mathrm{D}^{2} \mathrm{R}^{2}=0,64^{* *}$ \\
\hline & 5 a 10 & $\mathrm{IEA}=0,97-0,0031 \mathrm{D}+0,00003 \mathrm{D}^{2} \quad \mathrm{R}^{2}=0,40^{*}$ & ns \\
\hline & 10 a 15 & ns & ns \\
\hline $\begin{array}{l}\text { (') } \mathrm{K}, \mathrm{Ca}, \mathrm{Mg} \\
\text { em cmol } \mathrm{kg}^{-1} \text {; } \\
\text { (2) } \mathrm{D}=\% \mathrm{da} \\
\text { argiloso e } 13 \text {. } \\
\text { (3) ns = nấo si }\end{array}$ & $\begin{array}{l}\text { dregs corresponde } \\
\text { ha }^{-1} \text { no } \mathrm{CH} \text { franco } \\
\text { ivo }(\mathrm{p}>0,05) \text {; }^{*}=s\end{array}$ & $\begin{array}{l}\text { nagnésio e alumínio trocáveis em } \mathrm{cmol}_{\mathrm{c}} \mathrm{kg}^{-1} ; \mathrm{SB}=\text { soma da } \\
\text { regados. } \\
\text { cessidade de calcário para elevar o } \mathrm{pH}_{\mathrm{H} 2 \mathrm{O}} \text { para } 6,0 \text { na cam } \\
\text { ivo }(0,01<\mathrm{p}<0,05) \mathrm{e}^{* *}=\text { significativo }(\mathrm{p}<0,01) \text { pelo teste }\end{array}$ & $\begin{array}{l}\mathrm{cmol}_{c} \mathrm{~kg}^{-1} ; \mathrm{CTC}_{\text {efet }}=\text { capacidade de troca de cátions efeti } \\
20 \mathrm{~cm}, 100 \%=28.000 \mathrm{~kg} \mathrm{ha}^{-1} \text { de dregs no CH franco- }\end{array}$ \\
\hline
\end{tabular}


verificaram aumentos lineares até $15 \mathrm{~cm}$, alcançando $\mathrm{pH}$ de 6,9 na camada superficial. Com uma dose de dregs equivalente a $50 \% \mathrm{CaCO}_{3}$, Albuquerque et al. (2002) observaram aumento do $\mathrm{pH}$ para 7,3 em um Cambissolo Húmico na camada de 0 a $5 \mathrm{~cm}$.

Concomitante às alteraçóes observadas nos teores de cátions básicos e no $\mathrm{pH}$ do solo, o teor de Alumíno trocável (Al) na camada de 0 a $5 \mathrm{~cm}$ reduziu de $6,6 \mathrm{cmol}_{\mathrm{c}} \mathrm{kg}^{-1}$ no $\mathrm{CH}$ franco-argiloso e de $1,9 \mathrm{cmol}_{\mathrm{c}} \mathrm{kg}^{-1}$ no $\mathrm{CH}$ franco-arenoso para zero nas doses máximas de dregs. Considerando que o teor de $\mathrm{Al}$ trocável torna-se zero quando o $\mathrm{pH}$ do solo é maior do que 5,5, e com base nas equaçôes ajustadas para o $\mathrm{pH}$ do solo, para zerar o $\mathrm{Al}$ na camada de 0 a $5 \mathrm{~cm}$ seriam necessários 10,3 $\mathrm{Mg} \mathrm{ha}^{-1}$ no $\mathrm{CH}$ franco-argiloso e 3,0 $\mathrm{Mg} \mathrm{ha}^{-1}$ de dregs no $\mathrm{CH}$ franco-arenoso (Tabelas $3 \mathrm{e}$ 4). Quanto à camada de 5 a $10 \mathrm{~cm}$, em ambos os solos, o $\mathrm{Al}$ trocável reduziu em $1,0 \mathrm{cmol}_{\mathrm{c}} \mathrm{kg}^{-1}$ nas maiores doses em comparaçáo à testemunha, contudo, independentemente da dose aplicada de dregs, os teores de Al trocável foram maiores que 5,7 e 1,3 $\mathrm{cmol}_{c} \mathrm{~kg}^{-1}$, respectivamente, no $\mathrm{CH}$

\section{(a)}

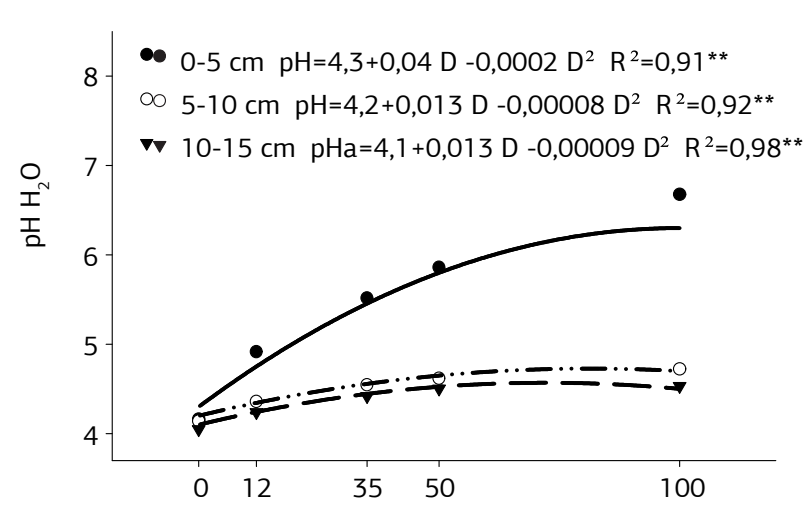

(c)

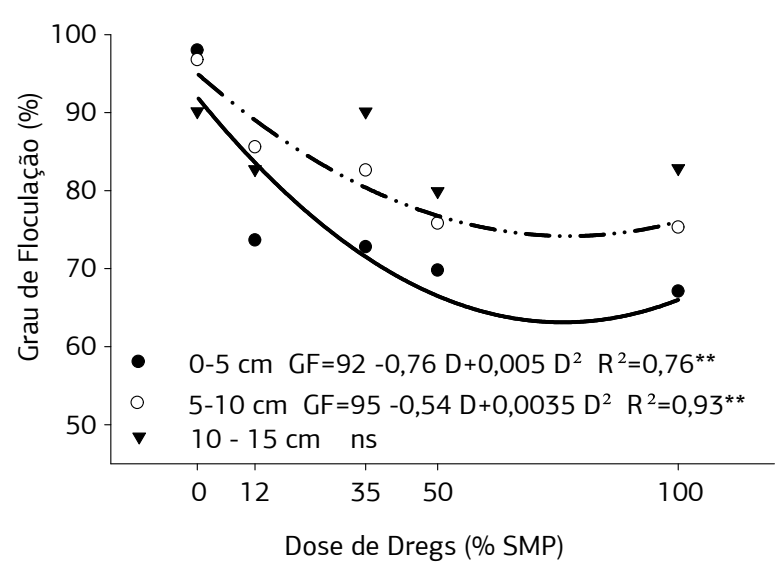

franco-argiloso e $\mathrm{CH}$ franco-arenoso. $\mathrm{Na}$ camada de 10 a $15 \mathrm{~cm}$, a maior dose de resíduo diminuiu o teor de $\mathrm{Al}$ trocável em apenas $0,2 \mathrm{cmol}_{\mathrm{c}} \mathrm{kg}^{-1}$, para ambos os solos.

AlbuQuerque et al. (2002) estudaram doses crescentes de dregs superficialmente em colunas e observaram que o $\mathrm{Al}$ reduziu para próximo de zero com as doses equivalentes a $12 \%$ de $\mathrm{CaCO}_{3}$ em Latossolo e a $25 \%$ de $\mathrm{CaCO}_{3}$ em um Cambissolo. Na camada de 5 a $10 \mathrm{~cm}$, a adição de resíduo não alterou os teores de $\mathrm{Al}$ após dois meses de sua aplicação.

A diminuição da acidez do solo está relacionada com a precipitação do $\mathrm{Al}$ e a dissociação do hidrogênio $(\mathrm{H})$ de grupos funcionais orgânicos e inorgânicos dos componentes sólidos do solo com o aumento do pH (ERNANI, 2008), diminuindo o Al na solução do solo.

Com a adição de cátions básicos ao solo, devido à aplicação do dregs, aumentou a soma de bases $(\mathrm{SB})$ nas três camadas avaliadas, porém com maior intensidade na camada de 0 a $5 \mathrm{~cm}$. Esse aumento e a redução da acidez elevaram de forma quadrática a $\mathrm{CTC}_{\text {efet }}$ na camada de $0 \mathrm{a} 5 \mathrm{~cm}$, de 7,5 para $10,4 \mathrm{cmol}_{c} \mathrm{~kg}^{-1}$ no $\mathrm{CH}$ franco-argiloso e de 2,6

(b)

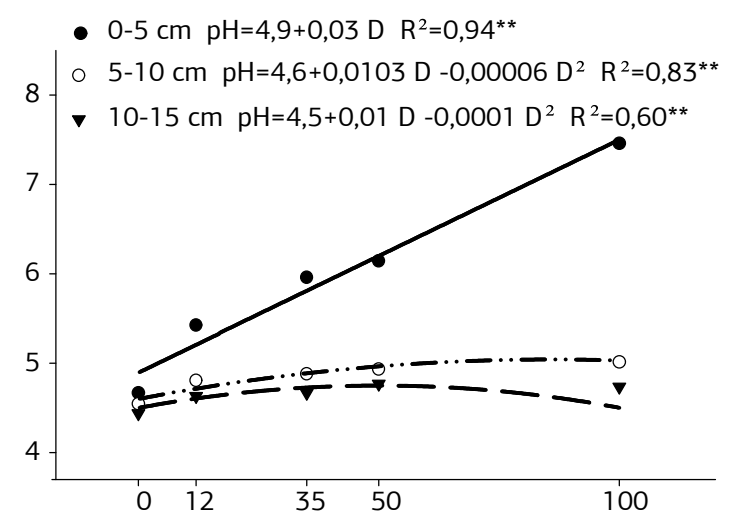

\section{(d)}

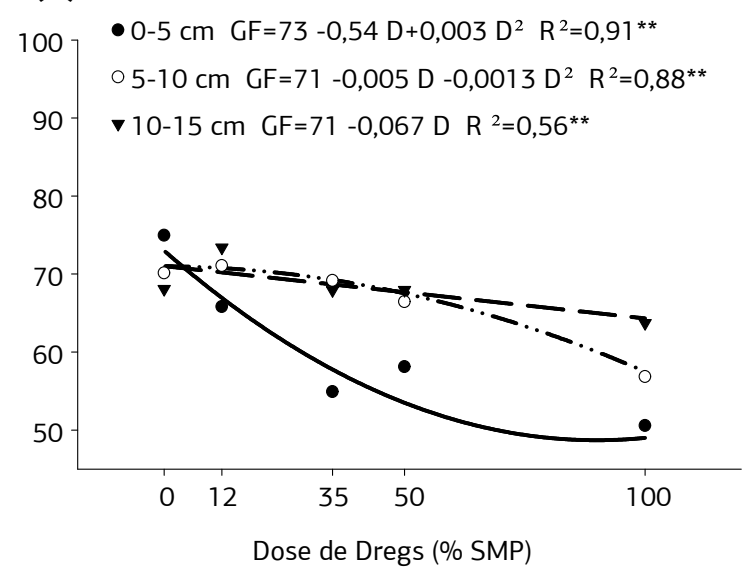

Figura 2. $\mathrm{pH}$ em água $\left(\mathrm{pH}_{\mathrm{H} 2 \mathrm{O}}\right.$ ) grau de floculação (GF) do Cambissolo Húmico de textura franco-argilosa (a, c) e do Cambissolo Húmico de textura franco-arenosa $(b, d)$, após incubação do solo com resíduo alcalino da indústria de papel e celulose, Lages (SC). D = \% da dose de dregs correspondente a necessidade de calcário para elevar o $\mathrm{pH}_{\mathrm{H} 2 \mathrm{O}}$ para 6,0 na camada de $0-20 \mathrm{~cm}, 100 \%=28.000 \mathrm{~kg}^{-1}$ de dregs no $\mathrm{CH}$ franco-argiloso e $13.100 \mathrm{~kg} \mathrm{ha}^{-1}$ no $\mathrm{CH}$ franco-arenoso. ns = não significativo; ${ }^{*}=$ significativo $(0,01<\mathrm{p}<0,05)$; $^{* *}=$ significativo $(\mathrm{p}<0,01)$. Cada ponto representa a média de três repetiçóes. 
para 5,8 $\mathrm{cmol}_{\mathrm{c}} \mathrm{kg}^{-1}$ no $\mathrm{CH}$ franco-arenoso (Tabelas 3 e 4). Essa ocorrência se deve às reaçôes químicas na solução e na superfície dos argilominerais do solo. Com a correção da acidez, os teores de $\mathrm{Al}$ e de $\mathrm{H}$ adsorvidos nas cargas permanentes e dependentes de $\mathrm{pH}$ diminuem, enquanto aumentam os teores de cátions básicos, processo que eleva a CTC efetiva do solo (CAIres et al., 2004). Nas demais camadas, a CTC efetiva permaneceu constante ou modificou pouco, pelo efeito da reduçáo do alumínio trocável, acompanhada ou náo pelo aumento na soma de bases.

No trabalho de AlbuQuerque et al. (2002), houve aumento da $\mathrm{CTC}_{\text {efet }}$ de 6 para $12 \mathrm{cmol}_{\mathrm{c}} \mathrm{kg}^{-1}$ em Cambissolo Húmico na camada de 0 a $5 \mathrm{~cm}$ com a aplicação superficial de dregs na dose correspondente a $50 \%$ de $\mathrm{CaCO}_{3}$. A calagem aumenta a $\mathrm{CTC}_{\text {efet }}$ em solos ácidos com predomínio de carga variável (AlbuQuerque et al., 2000), como é o caso da maioria dos solos do Sul do Brasil. Conforme o pH do solo aumenta, o Al sofre hidrólise, deixando vagos sítios de troca de cátions, ou ainda ocasiona a dissociação do hidrogênio de compostos orgânicos (CAMARGo et al., 1997).

Com todas as alteraçóes discutidas até o momento, a adição de dregs alterou a energia de atração e/ou repulsão do solo, consequentemente, o grau de floculação também foi modificado. O grau de floculação da argila (GF) reduziu de forma quadrática, nas camadas de 0 a 5 e 5 a 10 $\mathrm{cm}$ nos dois solos. Na camada de 10 a $15 \mathrm{~cm}$ permaneceu constante no $\mathrm{CH}$ franco-argiloso e reduziu de forma linear no $\mathrm{CH}$ franco-arenoso (Figura 2c,d).

Como ambos os solos possuem cargas permanentes e também dependentes do $\mathrm{pH}$, a correção da acidez elevou o número de cargas dependentes do $\mathrm{pH}$, e aumentou a repulsão das partículas de solo, conforme constatado também por Agassi et al. (1981) e Albuquerque et al. (2002). Outro fator que contribuiu para reduzir o grau de floculaçáo foi o aumento no teor de $\mathrm{Na}$ do solo (Figura 1a,b), em razão de sua alta concentração na composição do dregs (Tabela 2).
A análise de correlação indica que o grau de floculação é maior nas amostras com maiores teores de $\mathrm{Al}$ trocável e diminui quando aumenta o $\mathrm{pH}$, o teor e a saturação por $\mathrm{Na}$ (Tabela 5 e Figura 3). Estes resultados corroboram
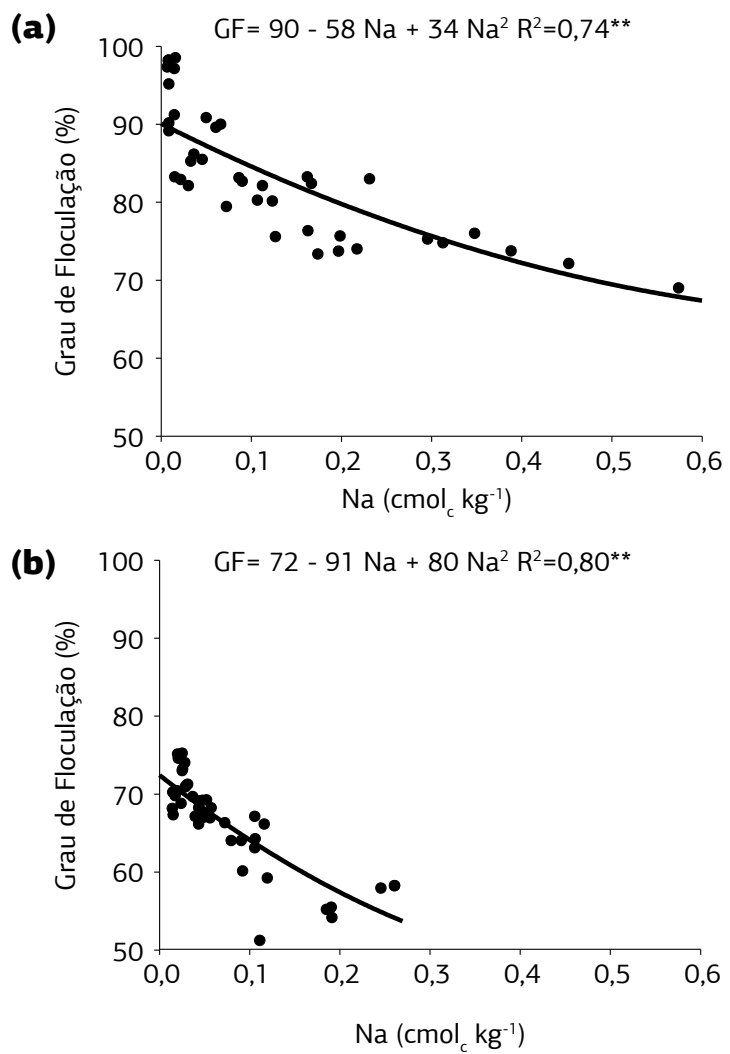

Figura 3. Relação entre grau de floculação e teor de sódio $(\mathrm{Na})$ do Cambissolo Húmico de textura franco-argilosa (a) e do Cambissolo Húmico de textura franco-arenosa (b), em função da aplicação superficial de doses crescentes de resíduo alcalino da indústria de papel e celulose, Lages $(\mathrm{SC}) .{ }^{* *}=$ significativo $(\mathrm{p}<0,01)$. Cada ponto representa uma unidade experimental.

Tabela 5. Análise de correlação de Pearson entre os atributos do Cambissolo Húmico de textura franco-argilosa (fonte negrito e itálico) e do Cambissolo Húmico de textura franco-arenosa (fonte normal), após incubação do solo com resíduo alcalino da indústria de papel e celulose, Lages (SC)

\begin{tabular}{|c|c|c|c|c|c|c|c|c|c|c|c|c|}
\hline & $\mathrm{Na}$ & K & $\mathrm{Ca}$ & Mg & $\mathrm{Ca} / \mathrm{Mg}$ & $\mathrm{SB}^{(1)}$ & Al & $\mathrm{pH}_{\mathrm{H} 2 \mathrm{O}}$ & CTC $_{\text {efet }}$ & IEA & GF & $\mathrm{VNa}$ \\
\hline $\mathrm{Na}$ & & $0,94^{* *}(2)$ & $0,94^{* *}$ & $0,87^{* *}$ & $0,93^{* *}$ & $0,95^{* *}$ & $-0,88^{* *}$ & $0,96^{* *}$ & $0,55^{* *}$ & $-0,13$ & $-0,76^{* *}$ & 0,96 ** \\
\hline K & $0,98^{* * *}$ & & $0,96^{* *}$ & $0,91^{* *}$ & $0,94^{* *}$ & $0,97^{* *}$ & $-0,90^{* *}$ & $0,92^{* *}$ & $0,54^{* *}$ & $-0,07$ & $-0,64^{* *}$ & $0,90^{* *}$ \\
\hline $\mathrm{Ca}$ & $0,92^{* *}$ & $0,95^{* *}$ & & $0,94^{* *}$ & $0,98^{* *}$ & $1,00^{* *}$ & $-0,93^{* *}$ & $0,95^{* *}$ & $0,55^{* *}$ & $-0,15$ & $-0,68^{* *}$ & $0,91^{* *}$ \\
\hline $\mathrm{Mg}$ & $0,76^{* *}$ & $0,81^{* *}$ & $0,92^{* *}$ & & $0,88^{* *}$ & $0,94^{* *}$ & $-0,94^{* *}$ & $0,9^{* *}$ & $0,38^{* *}$ & $-0,2$ & $-0,69^{* *}$ & $0,88^{* \prime}$ \\
\hline $\mathrm{Ca} / \mathrm{Mg}$ & $0,87^{* *}$ & $0,89^{* *}$ & $0,94^{* *}$ & $0,78^{* *}$ & & $0,98^{* *}$ & $-0,92^{* *}$ & $0,94^{* *}$ & $0,51^{* *}$ & $-0,09$ & $-0,69^{* *}$ & $0,91^{* *}$ \\
\hline SB & $0,94^{* *}$ & $0,96^{* *}$ & $1,00^{* *}$ & $0,92^{* *}$ & $0,94^{* *}$ & & $-0,94^{* *}$ & $0,96^{* *}$ & $0,55^{* *}$ & $-0,15$ & $-0,69^{* *}$ & $0,92^{* *}$ \\
\hline $\mathrm{Al}$ & $-0,73^{* *}$ & $-0,76^{* *}$ & $-0,9^{* *}$ & $-0,88^{* *}$ & $-0,89^{* *}$ & $-0,88^{* *}$ & & $-0,92^{* *}$ & $-0,22$ & 0,09 & $0,74^{* *}$ & $-0,93^{* *}$ \\
\hline $\mathrm{pH}_{\mathrm{H} 2 \mathrm{O}}$ & $0,93^{* *}$ & $0,94^{* *}$ & $0,98^{* *}$ & $0,88^{* *}$ & $0,93^{* *}$ & $0,98^{* *}$ & $-0,87^{* *}$ & & $0,45^{* *}$ & $-0,16$ & $-0,80^{* *}$ & $0,95^{*}$ \\
\hline CTC $_{\text {efet }}$ & $0,90^{* *}$ & $0,89^{* *}$ & $0,81^{* *}$ & $0,67^{* *}$ & $0,69^{* *}$ & $0,83^{* *}$ & $-0,47^{* *}$ & $0,80^{* *}$ & & $-0,19$ & $-0,16$ & $0,34^{*}$ \\
\hline IEA & $-0,11$ & $-0,11$ & $-0,18$ & $-0,20$ & $-0,20$ & $-0,18$ & 0,25 & $-0,19$ & $-0,03$ & & 0,19 & $-0,11$ \\
\hline GF & $-0,77^{* *}$ & $-0,74^{* *}$ & $-0,79^{* *}$ & $-0,69^{* *}$ & $-0,79^{* *}$ & $-0,79^{* *}$ & $0,83^{* *}$ & $-0,81^{* *}$ & $-0,50^{* *}$ & 0,29 & & $-0,81^{* *}$ \\
\hline $\mathrm{VNa}$ & $0,94^{* *}$ & $0,93^{* *}$ & $0,93^{* *}$ & $0,80^{* *}$ & 0,92* & $0,94 *$ & $-0,87^{* *}$ & $0,95^{* *}$ & $0,73^{* *}$ & $-0,22$ & $-0,90^{* *}$ & \\
\hline
\end{tabular}

(') $\mathrm{Ca} / \mathrm{Mg}=$ relação cálcio/magnésio; $\mathrm{SB}=$ soma das bases; $\mathrm{CTC}_{\text {efet }}=$ capacidade de troca de cátions efetiva; IEA= índice de estabilidade de agregados; $\mathrm{GF}=$ grau de floculação da argila; $\mathrm{VNa}=$ saturação por Sódio.

$\left.{ }^{(}\right)$ns = náo significativo $(\mathrm{p}>0,05) ;^{*}=$ significativo $(0,01<\mathrm{p}<0,05) \mathrm{e}^{* *}=$ significativo $(\mathrm{p}<0,01)$ para o teste $\mathrm{H}_{0}:|\mathrm{r}|=$ zero. 
os de Albuquerque et al. (2002) que observaram o efeito dispersante do dregs um Cambissolo Húmico Alumínico franco-argiloso e não observaram efeito dispersante no Latossolo Bruno, indicando que a dispersão da argila é dependente da mineralogia do solo. A aplicaçấo de doses elevadas de calcário em Latossolos aumentou a carga líquida negativa com o aumento do $\mathrm{pH}$ e reduziu o grau de floculação da argila (Morelli e Ferreira, 1987; Albuquerque et al., 2002).

O sódio dispersa a argila, pois é elemento monovalente e com grande raio hidratado, e em grande quantidade, torna os solos mais suscetíveis ao selamento superficial, diminui a infiltração de água no perfil e favorece a erosão hídrica (Reichert e Norton, 1994; 1996). Entretanto, devido à elevada concentraçáo eletrolítica da solução com cátions bivalentes adicionados com o dregs, o efeito dispersivo pode ser amenizado, em razão de permitir a predominância de pontes de cátions e as forças atrativas de curto alcance, que atraem as partículas (Agassi et al., 1981, VAN Olphen 1977; Mc Bride, 1989), assim os problemas advindos com a dispersão, como selamento superficial e erosão hídrica, diminuem (Miller e BaHARUdDin, 1986; Shainberg e Singer, 1988).
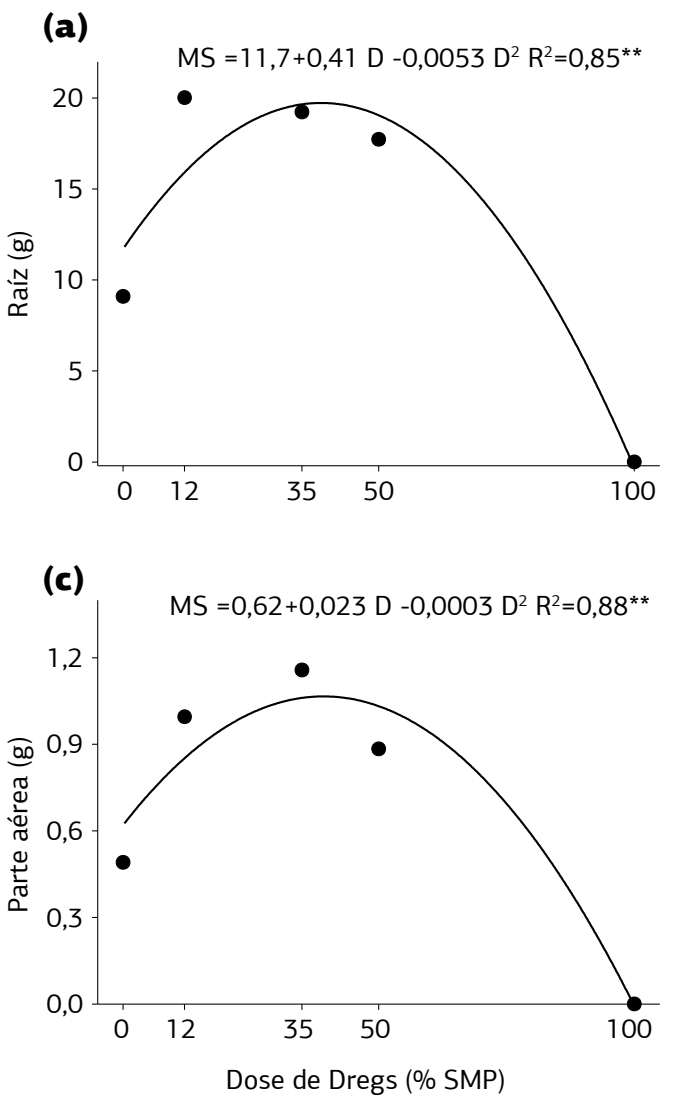

O índice de estabilidade dos agregados (IEA) diferiu entre as doses aplicadas de forma quadrática na camada de 5 a $10 \mathrm{~cm}$ no $\mathrm{CH}$ franco-argiloso e na camada de 0 a $5 \mathrm{~cm}$ do $\mathrm{CH}$ franco-arenoso, sendo os menores índices observados nas doses correspondentes a $50 \%$ em ambos os solos. Devido à estruturação natural desses Cambissolos, mesmo existindo diferenças no IEA entre as doses de dregs em algumas camadas, a amplitude do IEA foi pequena, pois, na camada de 0 a $5 \mathrm{~cm}$, por exemplo, variou de 0,90 a 0,95 no $\mathrm{CH}$ franco-argiloso e de 0,82 a 0,93 no $\mathrm{CH}$ franco-arenoso. Em um Cambissolo Húmico, Medeiros et al. (2009), avaliando a estabilidade de agregados na camada de 0 a 5 cm após 27 meses da aplicação de dregs na superfície, relataram aumento da estruturação nas doses menores e, predomínio do efeito dispersante dos elementos químicos sobre os efeitos agregantes nas maiores doses; contudo, a variação do diâmetro médio geométrico (DMG) foi de apenas 0,02 $\mathrm{mm}$. Esses efeitos são mais intensos se o resíduo tiver maior quantidade de $\mathrm{Na}$, fator que é variável com o lote de resíduo e o processo utilizado em cada indústria.

As modificaçóes nos atributos dos solos pela aplicação de resíduo alcalino se refletiram na produção de massa seca da parte aérea e das raízes do milho (Figura 4). Com
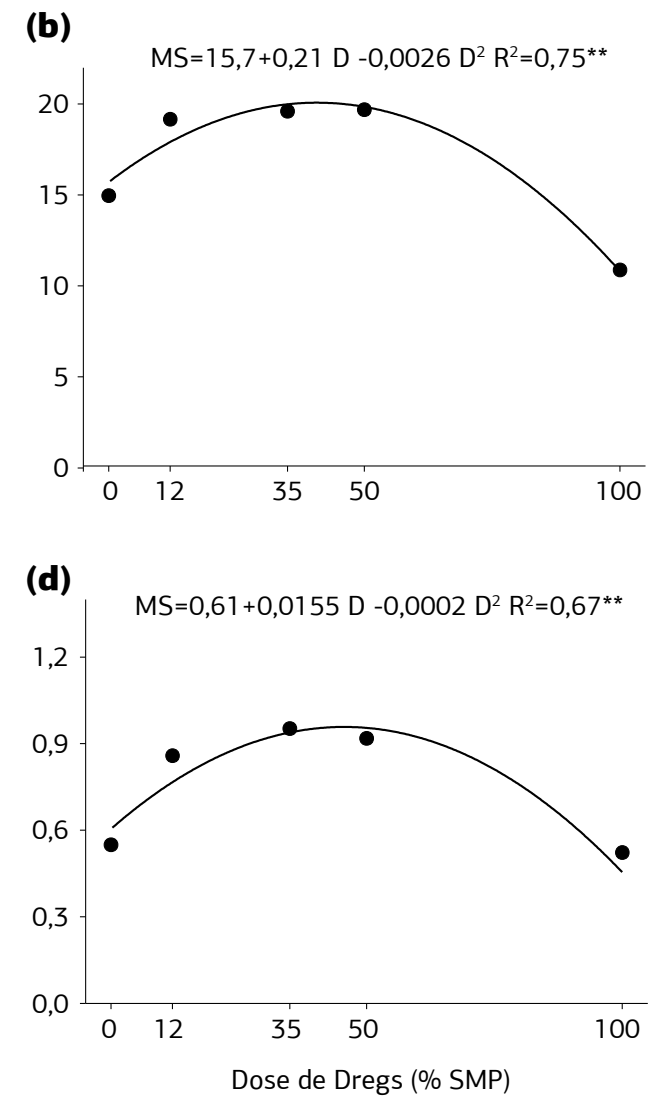

Figura 4. Produção de matéria seca (MS) das raízes e da parte aérea das plantas de milho cultivadas no Cambissolo Húmico franco-argiloso $(\mathrm{a}, \mathrm{c})$ e Cambissolo Húmico franco-arenoso (b,d), em funçáo da aplicação superficial de doses crescentes de resíduo alcalino da indústria de papel e celulose, Lages. $\mathrm{D}=\%$ da dose de dregs correspondente a necessidade de calcário para elevar o $\mathrm{pH}{ }_{\mathrm{H} 2 \mathrm{O}}$ para 6,0 na camada de 0-20 cm, 100\% = $28.000 \mathrm{~kg} \mathrm{ha}^{-1}$ de dregs no $\mathrm{CH}$ franco-argiloso e $13.100 \mathrm{~kg} \mathrm{ha}^{-1}$ no $\mathrm{CH}$ franco- arenoso. ${ }^{* *}=$ significativo $(\mathrm{p}<0,01)$. Cada ponto representa a média de três repetições. 
base nas equaçóes ajustadas, a produção de massa seca da parte aérea foi maior na dose de dregs correspondente a $39 \%$ da necessidade de $\mathrm{CaCO}_{3}$ para elevar o $\mathrm{pH}$ em água para 6,0 no $\mathrm{CH}$ franco-argiloso e a $47 \%$ no $\mathrm{CH}$ francoarenoso, enquanto a massa seca das raízes foi maior na dose correspondente a $40 \%$ para ambos os solos. A aplicação de doses superficiais maiores do que as detalhadas acima podem prejudicar o acúmulo de massa seca da parte aérea e de raiz do milho.

Em experimento realizado em campo em um Cambissolo Húmico alumínico Medeiros et al. (2009) observaram aumento da produtividade das culturas de trigo até a dose de dregs correspondente a $100 \%$ da quantidade de corretivo recomendada para elevar o $\mathrm{pH}$ até 6,0. Essa diferença pode estar associada à maior reatividade do resíduo e mobilidade no perfil do solo comparado com o que ocorre em vasos, proporcionando melhorias nas propriedades químicas em camadas mais profundas com a lixiviação, além de evitar acúmulo de elementos e grande alteraçáo do $\mathrm{pH}$, principalmente na camada mais superficial do solo.

$\mathrm{O}$ efeito favorável do dregs se deve à elevaçáo do $\mathrm{pH}$, neutralização dos cátions ácidos e adição de cátions básicos, enquanto o efeito prejudicial pode estar associado ao excesso de sódio no solo em doses elevadas (Medeiros et al., 2009). Outro efeito negativo é o desbalanço de nutrientes, posto que a relação $\mathrm{Ca} / \mathrm{Mg}$ é muito elevada no resíduo. Essa elevada relação $\mathrm{Ca} / \mathrm{Mg}$ pode inibir a absorção de $\mathrm{Mg}$ e $\mathrm{K}$, reduzindo a altura e a produção de massa seca da cultura quando a aplicação de corretivos torná-la superior a 8:1 no solo (Medeiros et al., 2008). Entretanto, o efeito prejudicial da alta relação $\mathrm{Ca} / \mathrm{Mg}$ ocorre somente em solos com deficiência de Mg (Oliveira e Parra, 2003; Medeiros et al., 2008).

\section{CONCLUSÃO}

A adição superficial de dregs eleva o $\mathrm{pH}$, os teores de $\mathrm{Ca}$, $\mathrm{K}$ e $\mathrm{Mg}$, e reduz o teor de $\mathrm{Al}$ trocável, principalmente na camada de 0 a $5 \mathrm{~cm}$. No entanto, são observados efeitos prejudiciais, como o aumento no teor de $\mathrm{Na}$, da relação $\mathrm{Ca} / \mathrm{Mg}$ e da dispersão da argila. As alteraçôes nos atributos químicos do solo favorecem o crescimento das raízes e da parte aérea do milho, até uma dose de dregs equivalente de $40 \%$ a $47 \%$ da necessidade de calcário para elevar o $\mathrm{pH}$ em água para 6,0. Doses superiores a essas prejudicam o desenvolvimento das plantas.

\section{AGRADECIMENTOS}

Os autores agradecem ao Conselho Nacional de Desenvolvimento Tecnológico e Científico (CNPq) pelo apoio financeiro ao projeto e pela concessão da bolsa de produtividade do primeiro autor e de iniciação científica do quarto autor.

\section{REFERÊNCIAS}

AGASSI, M.; SHAINBERG, I.; MORIN, J. Effect of electrolyte concentration and soil sodicity on infiltration rate and crust formation. Soil Science Society American Journal, v.45, p.848$851,1981$.

ALBUQUERQUE, J.A; ARGENTON, J.; FONTANA, E.C; COSTA, F.S.; RECH, T.D. Propriedades físicas e químicas de solos incubados com resíduo alcalino da industria de celulose. Revista Brasileira de Ciência do Solo, v.26, p.1065-1073, 2002.

ALBUQUERQUE, J.A.; BAYER, C.; ERNANI, P.R.; FONTANA, E.C. Propriedades físicas e eletroquímicas de um Latossolo Bruno afetadas pela calagem. Revista Brasileira de Ciência do Solo, v.24, p.295-300, 2000.

ALMEIDA, H.C.; ERNANI, P.R.; ALBUQUERQUE, J.A.; MECABÔ JUNIOR, J.; ALMEIDA, D. Influência da adição de um resíduo alcalino da indústria de papel e celulose na lixiviação de cátions em um solo ácido. Revista Brasileira de Ciência do Solo, v.32, p.1775-1784, 2008.

CAIRES, E.F.; KUSMAM, M.T.; BARTH, G.; GARBUIO, F.G.; PADILHA, J.M. Alterações químicas do solo e resposta do milho à calagem e aplicação de gesso. Revista Brasileira de Ciência do Solo, v.28, p.125-136, 2004.

CAMARGO, O.A.; CASTRO, O.M.; VIEIRA, S.R.; QUAGGIO, J.A. Alteraçóes de atributos químicos do horizonte superficial de um Latossolo e um Podzólico com a calagem. Scientia Agricola, v.54, p.1-8, 1997.

COMISSÃO DE QUÍMICA E FERTILIDADE DO SOLO - RS/ SC. Manual de adubação e calagem para os Estados do Rio Grande do Sul e de Santa Catarina. 10.ed. Porto Alegre, SBCS - Núcleo Regional Sul/UFRGS, 2004. 400p.

CORREA,J.C; BÜLL, L.T.; CRUSCIOL, C.A.C.; FERNANDES, D.M.; PERES, M.G.M. Aplicaçáo superficial de diferentes fontes de corretivos no crescimento radicular e produtividade da aveia preta. Revista Brasileira de Ciência do Solo, v.32, p.1583-1590, 2008.

EMPRESA BRASILEIRA DE PESQUISA AGROPECUÁRIA - EMBRAPA. Centro Nacional de Pesquisa de Solos. Manual de Métodos de Análise de Solo. 2.ed. Rio de Janeiro, 1997. 212p.

ERNANI, P.R. Química do solo e disponibilidade de nutrientes. Lages: O autor, 2008. 230p.

FLORES, D.M.M.; FRIZZO, S.M.B.; FOELKEL, C.E.B. Tratamentos alternativos do efluente de uma indústria de celulose branqueada e papel. Ciência Florestal, v.8, p.93-107, 1998.

GARDNER, W.H. Water Content. In: BLACK, C.A. (Ed.). Methods of soil analysis- Physical and mineralogical methods. 2.ed. Madison: American Society of Agronomy, Soil Science Society of America, 1986. p.493-544.

GEE, G.W.; BAUDER, J.W. Particle-size analysis. In: KLUTE, A. (Ed.). Methods of soil analysis - Physical and mineralogical methods. 2.ed. Madison: American Society of Agronomy, Soil Science Society of America, 1986. p.383-411. 
JOHNSON, B.; RYDER, I. The disposal of pulp and papper mill effluents by spray irrigation onto farmland. In: BHAMIDIMARRI, R. (Ed.). Alternative Waste Treatment Systems. New York: Elsevier, 1988. p. 55-65.

KEMPER, W.D.; ROSENAU, R.C. Aggregate stability and size distribution. In: KLUTE, A. (Ed.). Methods of soil analysis. 2.ed. Madison: American Society of Agronomy, Soil Science Society of America, 1986. p.425-441.

KOOKANA, R.S.; ROGERS, S.L. Effects of pulp mill effluent disposal on soil. Reviews of Environmental Contamination and Toxicology, v.142, p.13-64, 1995.

Mc BRIDE, M.B. Surface chemistry of soils minerals. In: DIXON, J.B.; WEED, S.B. (Ed.). Minerals in soil environments. 2.ed. Madison: Soil Science Society of America, 1989. p.35-88.

MEDEIROS, J.C.; ALBUQUERQUE, J.A.; MAFRA, A.L.; ROSA, J.D.; GATIBONI, L.C. Relaçáo cálcio:magnésio do corretivo da acidez do solo na nutriçáo e no desenvolvimento inicial de plantas de milho em um Cambissolo Húmico Álico. Semina: Ciências Agrárias, v.29, p.799-806, 2008.

MEDEIROS, J.C.; ALBUQUERQUE, J.A.; MAFRA, A.L.; BATISTELA, F.; GRAH J. Calagem superficial com resíduo alcalino da indústria de papel e celulose em um solo altamente tamponado. Revista Brasileira de Ciência do Solo, v.33, p.1657-1665, 2009.

MILLER, W.P.; BAHARUDDIN, M.K. Relationship of soil dispersibility to infiltration and erosion of southeastern soils. Soil Science, v.14, p.235-240, 1986.

MORELLI, M.; FERREIRA, E. B. Efeito do carbonato de cálcio e do fosfato diamônico em propriedades eletroquímicas e físicas de um Latossolo. Revista Brasileira de Ciência do Solo, v.11, p.1-6, 1987.
OLIVEIRA, E.L.; PARRA, M.S. Resposta do feijoeiro a relaçóes variáveis entre cálcio e magnésio na capacidade de troca de cátions de Latossolos. Revista Brasileira de Ciência do Solo, v.27, p.859866, 2003.

PÖOYKIÖ, R.; NURMESNIEMI, H.; KUOKKANEN, T.; PERÄMÄKI, P. Green liquor dregs as an alternative neutralizing agent at a pulp mill. Environmental Chemistry Letters, v.4, p.3740, 2006

REICHERT, J.M.; NORTON, D.L. Fluidized bed bottom-ash effects on infiltration and erosion of swelling soils. Soil Science Society American Journal, v.58, p.1483-1488, 1994.

REICHERT, J.M.; NORTON, D.L. Fluidized bed combustion bottom-ash effects on infiltration and erosion of variablecharge soils. Soil Science Society American Journal, v.60, p.275-282, 1996.

SAS. Statistical analysis system. Getting Started with the SAS Learning Edition. Cary, North Carolina: SAS Institute, 2002. 86p.

SHAINBERG, I.; SINGER, M.J. Drop impact energy-soil exchangeable sodium percentage interactions in seal formation. Soil Science Society American Journal, v.52, p.1449-1452, 1988.

SPRINGER, A.M. Industrial Environmental Control - Pulp and Paper Industry. Atlanta: Tappi Press, 1993. 699p.

TEDESCO, M.J.; GIANELLO, C.; BISSANI, C.A.; BOHNEN, H.; VOLKWEISS, S.J. Análises de solos, plantas e outros materiais. 2.ed. Porto Alegre: Departamento de Solos UFRGS, 1995. 174p. (Boletim Técnico 5)

VAN OLPHEN, H. An introduction to clay colloid chemistry. 2.ed. New York: John Willey, 1977. 318p. 